to have been most promising and most complete in tochnical detail. How many other investigators have come as olose to success with the problem, but have been interrupted by war-work or other circumstances, we may never know.

1Phys. Rev., 48, 217 (1933).

'T.S. Patent 1,645,304.

- Carnegie Year Book, No. 27, 209 (1927-28).

- Arch. Electrotech., 2, 400 (1928).

- Proc. (lamh. Phil. Soc., 25, 469, part 4 (Oct. 1929).

' Jassinsky, W. W., Arch. Electrotech., 30, 500 (1936).

'Steenbeck, M., U.S. Patent 2,103,203.

- Steenbeck, M., Phys. Z. (Feb. 1943).

'Penny, G. W., U.S. Patent 2,193,802.

"Kerst, D. W., and Serber, R., Pkyz. Rev., 60, 53 (1941).

"Kerst, D. W., Phys. Rev., 60, 47 (July 1, 1941).

\section{MICROBIOLOGY, BIOCHEMISTRY, AND THE GENETICS OF MICRO-ORGANISMS}

\author{
By Dr. G. PONTECORVO
}

Institute of Animal Genetics, University of Edinburgh

$\mathrm{I}$

$\mathrm{N}$ the last fow years certain important advances have been made in the genetics of micro-organisms. Their implications are fundamental for genetics and go far beyond it, since they forecast a synthesis with microbiology, immunology and biochemistry. It is therefore fortunate that a very suggestive view of the whole field is now available in the form of a special issue of the Annals of the Missouri Botanical Garden*, containing the papers read, and the ensuing discussion, at a conference on "Gene Action in Microorganisms" held last February at St. Louis. The volume should be read by all those interested in the general trends of biology.

For the study of heredity and variation in higher organisms the geneticist has had to avoid many pitfalls, some of which are of everyday occurrence also with micro-organisms. For example, the microbiologist has often to decide whether a change in a strain is a direct consequence of certain external conditions or of selection under such conditions. Collaboration with the geneticist can here be very fruitful, as shown in the papers by Demerec, Delbrück, Spiegelman, Luria, Hollaender and Gowen at the Conference. But the advantage is reciprocal, since the microbiologist holds in store an impressive mass of facts having direct bearing on genetics. $\mathrm{He}$ can, for example, point out that in most groups of Fungi (and, I would suggest, probably in Protozoa with plasmodial stages) genetic systems of an "entirely unexplored kind are the rule. They are based on 'heterokaryosis', instead of heterozygosis; that is, on the presence of genetically different nuclei in a

* Ann. Missouri Bot. Garden, 2, No. 2 (1945), Conference on "Gene Action in Microorganisms".

Lindegren, C. C., "Mendelian and Cytoplasmic Inheritance in Yeasts." Trbum, E. L., and Beadle, G. W., "Biochemical Genetics of Neurospora."

Demerec, M., "Genetic Aspects of Changes in Staphylococcus aureus Producing Strains Resistant to Various Concentrations of Penicillin." Spiegelman, S., "The Physiology and Genetic Signiflcance of Enzymatic Adaptation."

Hollaender, A., "The Mechanism of Radiation Effects and the Use of Radiation for the Production of Mutations with Improved Fermentation."

Greenstein, J. P., and Chalkley, H. W., "The Influence of Nucleic Acld on Dehydrogenase Systems."

Gowen, J. W., "Genetic Aspects of Virulence in Bacteris and Viruses." Sonneborn, T. M." "Gene Action in Paramecium."

Delbrick, M., "Spontaneous Mutations of Bacteris."

Luria, S. E." "Genetics of Bacterium-Bacterial Virus Relationship." Emerson, S., "Genetics as a Tool for Studying Gene Structure." Discussion. multinucleate cell, instead of genetically different sets of chromosomes in the diploid, or polyploid, nucleus of a uninucleate cell.

The recent developments in the genetics of microorganisms have led to important advances in direc. tions other than heredity and variation. A fascinating field is that opened up with the attempt by Sturtevant and Emerson to introduce immunological concepts and techniques in the study of the nature of genes. The mode of inheritance of cell antigens in vertebrates prompted Haldane to suggest long ago that there might be a structural relationship between gene and antigen. On this basis Sturtevant has raised the question of whether antibodies against natural antigens might induce specific mutations in the corre. sponding genes, an idea that Hindle had independently suggested to me. A preliminary experimental attempt by Emerson with the mould Neurospora has given encouraging, but by no means adequate, results. In the meantime, Emerson has made an interesting formal analysis of the possible structural relationships between gene and gene-product which considers gene reproduction and gene action as two complementary aspects of the same activity, somewhat like a key moulding its key-hole and the key-hole moulding the key. Clearly, if results are forthcoming, one of the most spectacular advances in genetics is 'round the corner'.

Another important field in which progress has been impressive is that of the genetic control of metabolic reactions. Up to five years ago, in very few cases had the action of genes been traced right down to the identification of elementary biochemical steps controlled by genes. The best-known example was that of the genetics of flower pigments. The work on the mould Neurospora by Beadle, Tatum and their associates at Stanford University has now added an impressive mass of far more complete examples. The general conclusion to which they have come is that each step in a chain of metabolic reactions is controlled by a specific gene. Since genes that have mutated, especially as a consequence of X-ray treatment, are often inactive, it is possible to block a metabolic step by producing a mutation in the corresponding gene. Much to the advantage of the biochemist, it follows that in a chain of metabolic resctions with an unknown number of steps, it is possible to identify the single steps and reconstruct the chain by identifying the genes involved.

There seems to be little doubt that the control by genes of elementary biochemical steps takes place through enzymes. This raises the question of the relations between gene and enzyme. The study of the inheritance of enzymes in yeast, started by Winge and developed by Lindegren and Spiegelman, suggests that the production, or better the specificity, of each enzyme is under the immediate control of a gene. We must, however, be cautious on this point, since so far the evidence only shows that the ability or inability to produce an enzyme is generally inherited as a Mendelian unit. It is a reasonable inference on general grounds-but nothing more than an inference - that, of two allelomorphs of a gene, one may determ. ine the production of one enzyme and the other that of a different enzyme. Clearly, this must be settled experimentally as soon as possible.

Granted that genes, or at least some genes, control enzyme specificity, it seoms to me that we have to find a way out of the following difficulty. The different enzymes of a cell, each under the immediate control of a specific gene, are produced at enormously 
different rates ; this is also true of the same enzyme in different cells of a multicellular organism. What is known of mitosis, on the other hand, suggests that all genes in a nucleus reproduce at the same rate. Uniless gene reproduction and gene action are totally independent of each other, we have to reconcile the uniformity in reproduction of the genes with the enormous variation in the output of what we believe to be their primary products. This is, of course, one way of looking at the problem of cell differentiation. Two series of important investigations may suggest a way out of this difficulty.

First, there are the findings of Spiegelman and Lindegren in yeast. A dominant gene is necessary for yeast cells to produce the 'adaptive' enzyme melibiozymase. In cells carrying the gene, the enzyme increases in amount with an autocatalytic trend when they are put in a medium containing melibiose; it disappears reversibly in a few hours when melibiose is removed. With appropriate crosses, cells can be obtained lacking the gene but carrying some melibiozymase in the cytoplasm : these cells can go on producing melibiozymase indefinitely, and for an indefinite number of generations, if kept in contact with melibiose; removal of melibiose brings about the irreversible loss of the enzyme.

Secondly, there is Sonneborn's remarkable work on Paramecium, only the essentials of which can be referred to here. Certain strains carry in the cytoplasm a 'kappa' substance which, released into the water, poisons it for other strains. With appropriate crosses, individuals can be obtained with the same genetic constitution as the former but lacking the 'kappa' substance in the cytoplasm. These individuals are unable to produce the 'kappa' substance unless some of it is introduced into the cytoplasm by means of special devices. The production of 'kappa' can also be blocked by suitable gene substitutions. In other words, 'kappa' is produced if some of it is present in the cytoplasm to start with and the genetic constitution is appropriate.

From these investigations and the stimulating discussion, especially by Muller, at the St. Louis Conference, I would like to draw the following very speculative picture. Enzymes, or similar proteins, occur in the cytoplasm, and can increase in amount autocatalytically if a trace is present to begin with. For this increase specific precursors, indirectly controlled by genes, are required. Furthermore, certain of these autocatalytic proteins, being unstable, can be maintained and increase in the cytoplasm only if specific substrates, intra- or extra-cellular, are available. Lastly, while those which are stable, or stabilized by ever-present intracellular substrates, can perpetuate themselves from cell to cell simply through cytoplasmic transmission, those which require a stabilizing extracellular substrate would be continually liable to be lost. There is, however, a safety mechanism : a specific gene keeps a trace of these unstable substances always ready; whenever the external substrate is provided, this trace can start the autocatalytic process independently of the specific gene. What the gene has to do is therefore only to synthesize an initial amount of the substance. Until we can give each its proper chemical status, there is no harm in lumping all these 'self-reproducing' substances, gene-initiated or otherwise, under the name of 'plasmagenes'. Those that can be transmitted externally from one cell to another, and there cause disease, may be viruses, as Darlington suggests. It is noteworthy that pathologists, starting from the virus end of the story, have long held more or less the same view.

Should the preceding picture be broadly correct, the large differences in output of different enzymes in a cell, and of the same enzyme in different cells, would be reconcilable with the view that most enzymes are primary gene products. We may conceive that all genes in a cell are, at any one time, working all at the same rate, say producing the same number of molecules of their different primary products; yet the actual amount of each in the cytoplasm will vary secondarily, depending, among other things, on its ability to increase autocatalytically, on the limiting amount of specific precursor, and on extra- or intracellular substrates. Since the presence of precursors and of intracellular substrates depends on the previous history of the cell, as pointed out by Spiegelman and Lindegren, there is here a basis for cell differentiation in time, each successively available precursor or substrate making possible the indepen. dent autocatalytic increase, and the activity, of new gene-initiated plasmagenes.

On the whole, the nucleus seems to emerge from these studies with enhanced prestige. Its control of the activities of the cell seems to be largely a one-way affair. No doubt the nuclear membrane holds a good deal of the secret, and it would be desirable to stert tackling it.

\section{INTERNATIONAL SCIENTIFIC CO-OPERATION}

\author{
By Prof. F. J. M. STRATTON, O.B.E. \\ General Secretary of the International Council of \\ Scientific Unions
}

7 HE gradual easing of restrictions on travel and on the general release of scientific discoveries has made it practicable once more to arrange international meetings of men of science. The general assembly of the International Council of Scientific Unions will meet in London during July 22-24, 1946. Meanwhile its Executive Committee has held a meeting in London attended by representatives of most of the International Unions adhering to the Council.

In welcoming the Committee at its opening session, Prof. A. V. Hill, foreign secretary of the Royal Society, pointed out that science in its own interest must remain an international concern and that the future of civilization itself depends upon the close co-operation of scientific men throughout the world. Taking as an example the field of medicine and the high ethical principles which have been developed therein, he emphasized the need for a common standard of ethical behaviour in science. "In standards of truthfulness and integrity, in readiness to co-operate with other scientists of good will everywhere, and in refusal to use the common knowledge, prestige and power of science for base, harmful and selfish ends, scientists should feel them. selves bound by an honourable and unbreakable obligation".

The heavy toll of recent years on those prominent in the field of international science was revealed by the list of members of the Committee who had died since its last meeting: Marconi and $J_{0 j i}$ Sakurai, vice-presidents ; Sir Arthur Eddington, president of the International Astronomical Union; Prof. Nicols 